\title{
EDIFICIO CENTRAL DE IFEMA EN MADRID-ESPAÑA
}

\author{
(THE CENTRAL PAVILION IN THE IFEMA FAIRGROUND. MADRID - SPAIN)
}

\author{
F. J. Sáez de Oiza, J. Sáez Guerra y F. Oiza Cuadrado, Arquitectos
} IFEMA

Fecha de recepción: 13.1-92

$691 \cdot 8$

\section{RESUMEN}

En el extremo Sur del Eje del recinto ferial de IFEMA, se alza su Pabellón Central. Pabellón de planta cuadrada, con un gran patio circular en su centro.

Aquí, se expone la composición de sus dos fachadas de vidrio claramente diferenciadas.

Una, la del patio, donde los paneles de vidrio de 1,25 $\times 3,00$ $\mathrm{m}$ en vidrio aislante, $10+\mathrm{c}+10$, encajan entre suelo y techo de los forjados, a base de una sencilla carpintería. En su retranqueo, nos ofrece una sutil superposición de planos, valiéndose de antepechos de chapa perforada y parasoles de vidrio.

Otra, la fachada exterior, que aparece como doble. De una parte, se mantiene el mismo sistema que en el patio, y de otra, se le superpone a éste en todo su perímetro "un muro cortina exento". Se define así, una gran galería en torno a todo el edificio que, debido a su ventilación superior y al espacio intermedio determinado, facilita la climatización del edificio.

La estructura que sustenta el muro cortina (junto con el sistema de pasarelas), la perfilería especial, y la dimensión de los paneles de vidrio $4,00 \times 2,50 \mathrm{~m}$ en vidrio aislante $12+c+10$, acusan la horizontalidad de la fachada.

\section{SUMMARY}

The Central Pavilion, with its square floor and a large circular central patio, rises in the southernmost point of the Axis of the IFEMA Fairground.

This article deals with the composition of its two clearly distinguished glass façades.

One, the one facing the patio, has glass panels of $1,25 \times 3,00 \mathrm{~m}$ in isolated glass, $10+c+10$, fitting between the floor and the roof of the slab by means of a simple woodwork. It offers a subtle superposition of plans with perforated veneer railing and glass sunscreens.

The exterior façade looms up as double. On one side, the same system as the one in the patio is maintained, on the other side an "open curtain wall" is located on top of the façade along its entire perimeter. In this way, a large gallery around the entire building is defined. Due to its upper ventilation and determined central space, the acclimatization of the building is provided.

The structure supporting the curtain wall (together with the system of aisles), the special cross-section and the dimensions of the glass panels $4,00 \times 2,50 \mathrm{~m}$ in isolated glass $12+c+10$ bring out the horizontality of the façade.

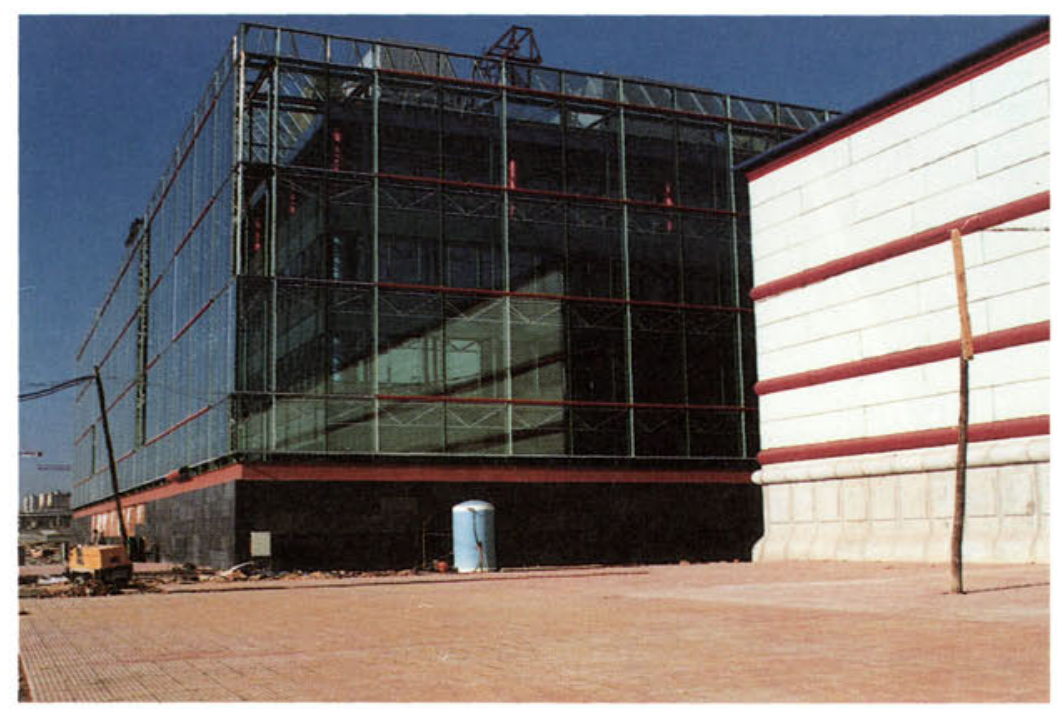




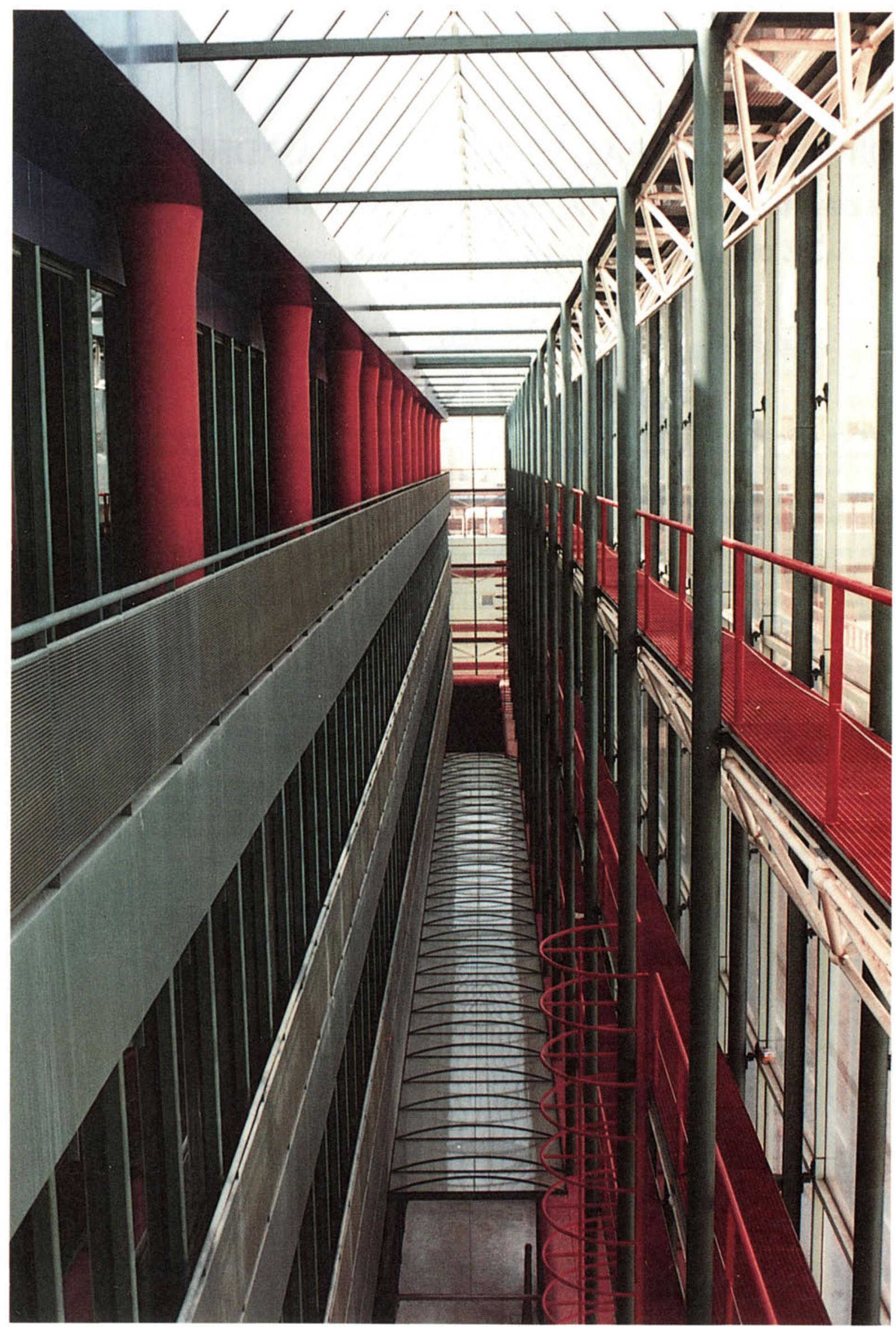




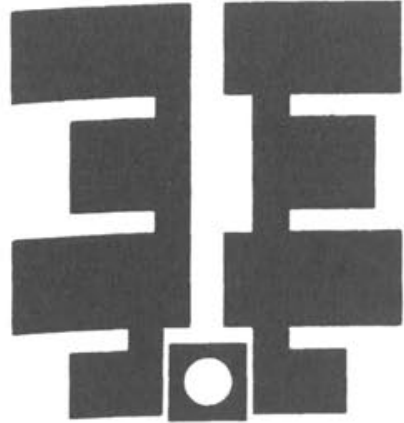

Esquema del Recinto Ferial de IFEMA.
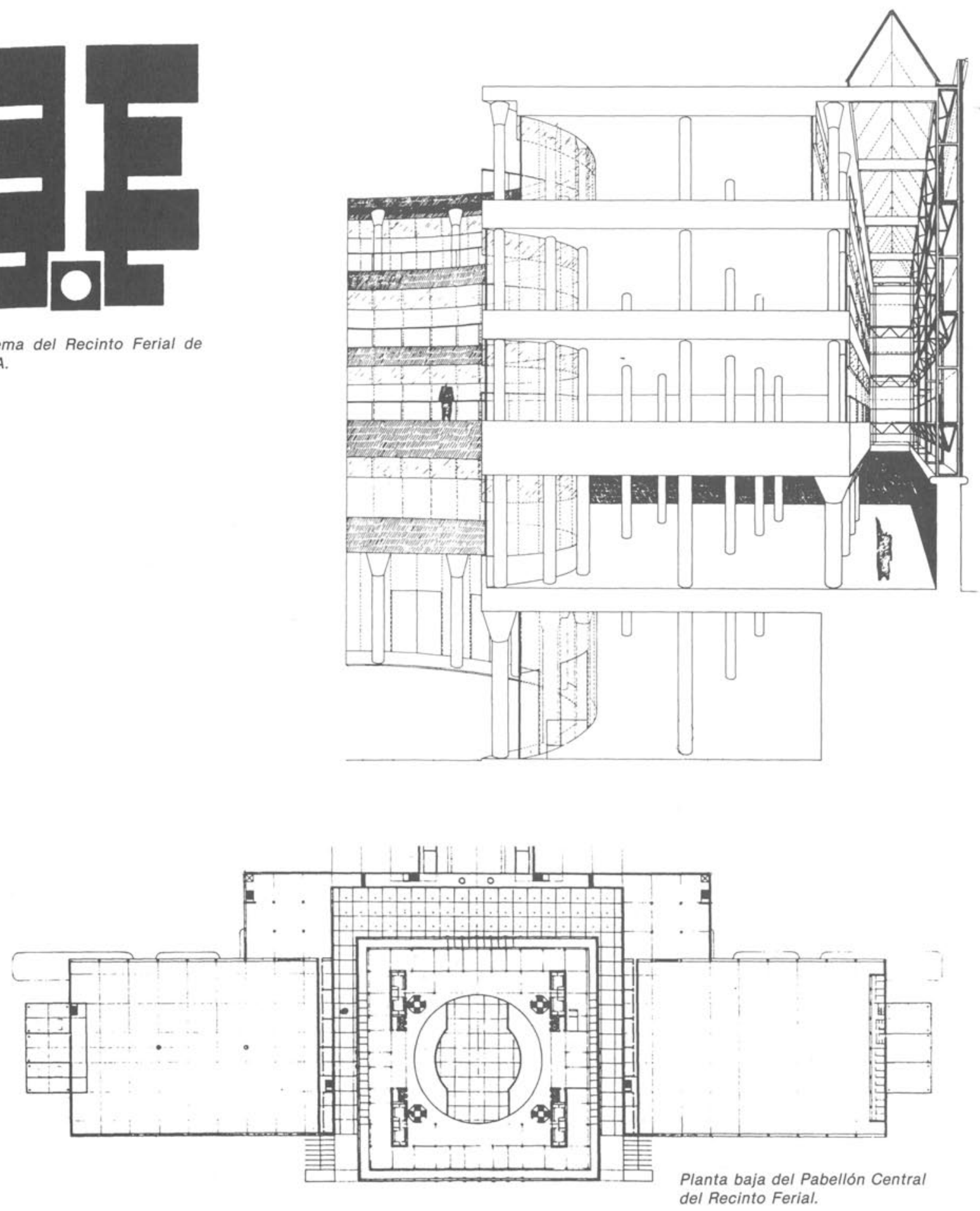

El edificio central del nuevo recinto ferial de IFEMA, en Madrid, aparece como hito representativo de dicho recinto. Su planta cuadrada, con un gran espacio abierto circular en su centro, nos recuerda el Palacio de Carlos V de Machuca, en la Alhambra (Granada). Se imbrica asi en un sistema espacial entre-abierto, como quiere ser el eje principal del Ferial. (De la memoria del Proyecto).

El edificio aparece como dos cajas de cristal una dentro de otra, definiendo un espacio perimetral diáfano que, en su grosor, sirve de acondicionamiento climático. Se crea asi una fachada compuesta de dos alzados superpuestos: uno exterior y otro interior. El exterior es denominado "Fachada Transventilada" (se ventila en su parte superior), y su existencia favorece el mantenimiento de las constantes climáticas para el aire de retorno. 

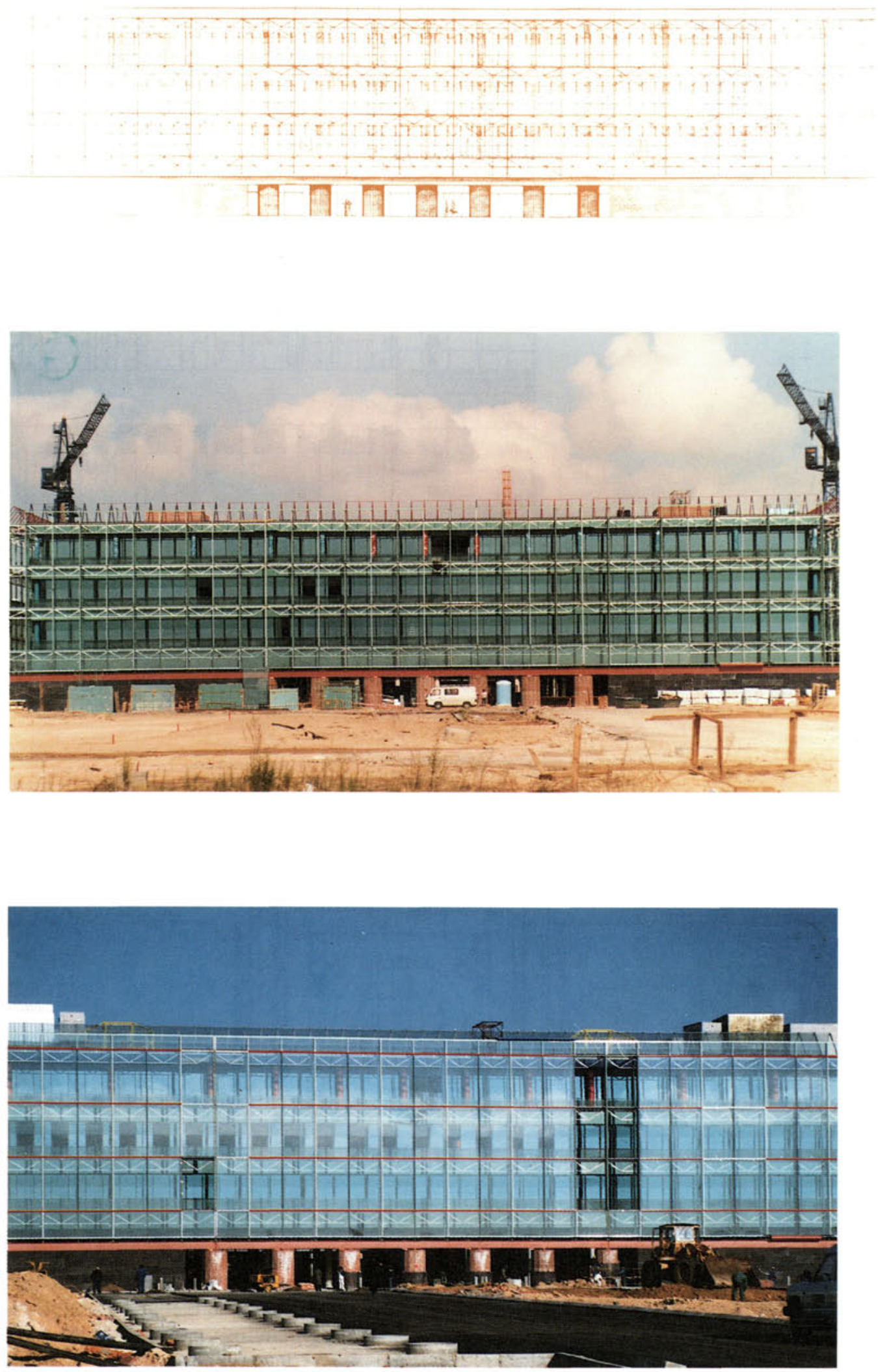


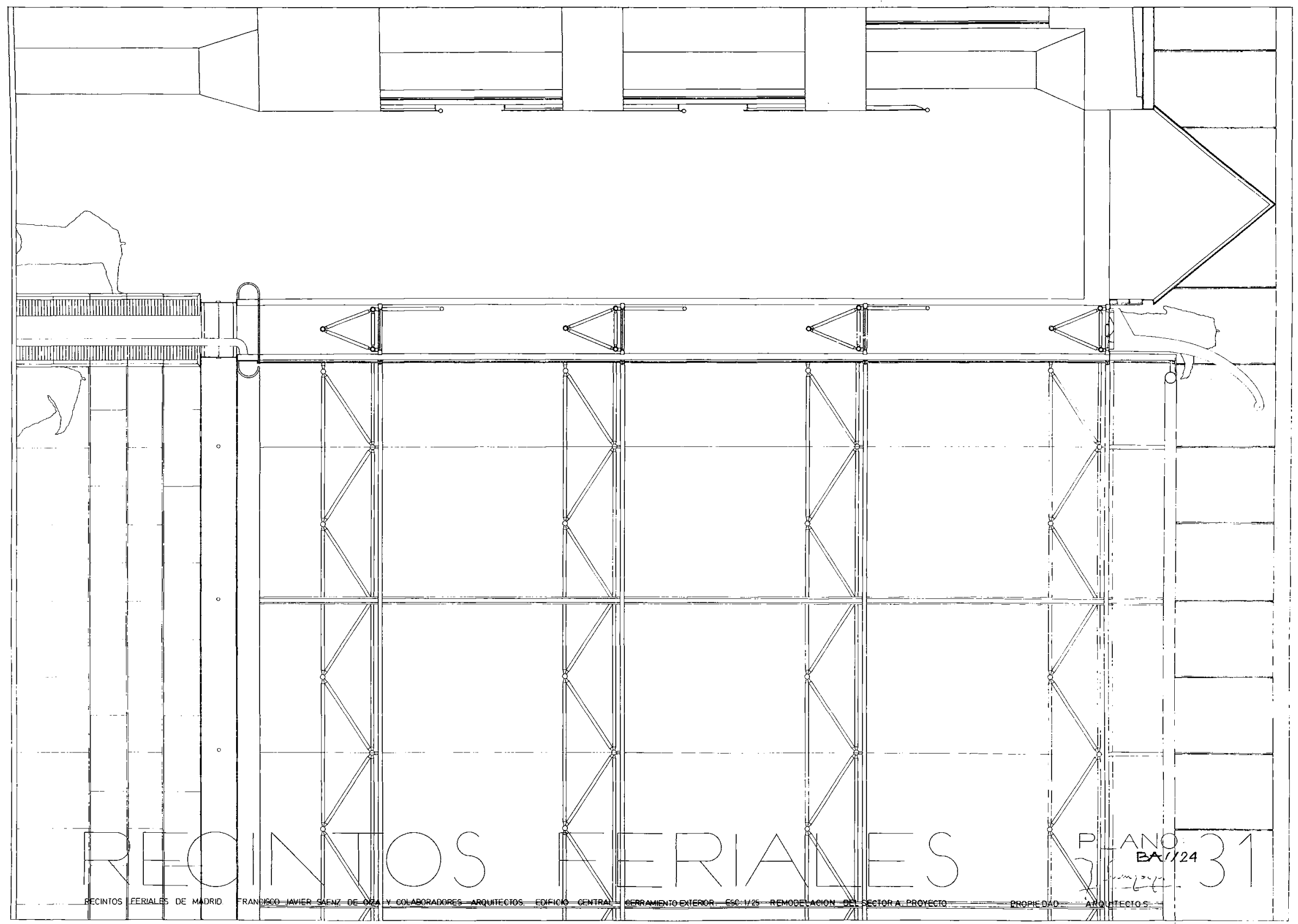




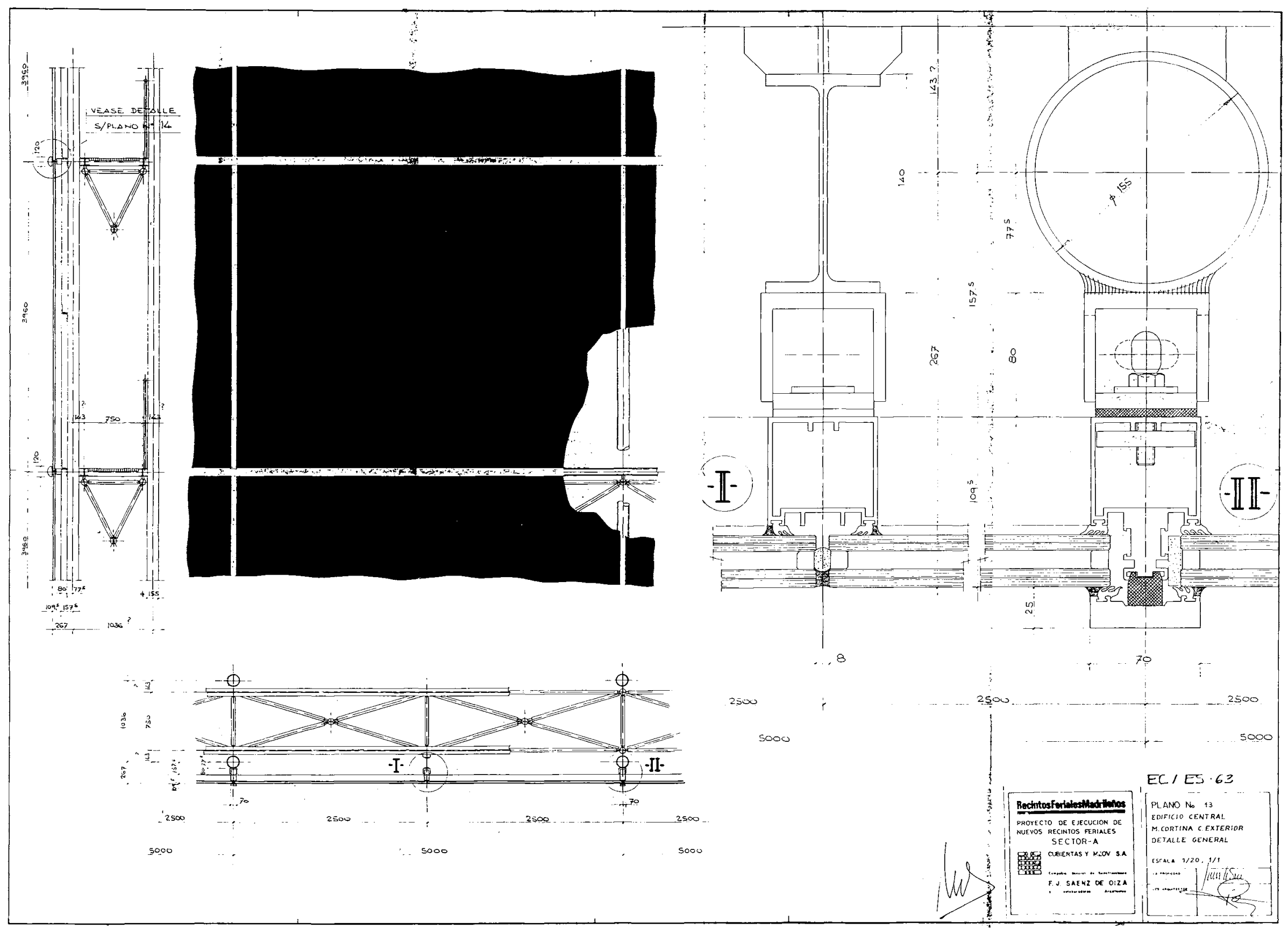




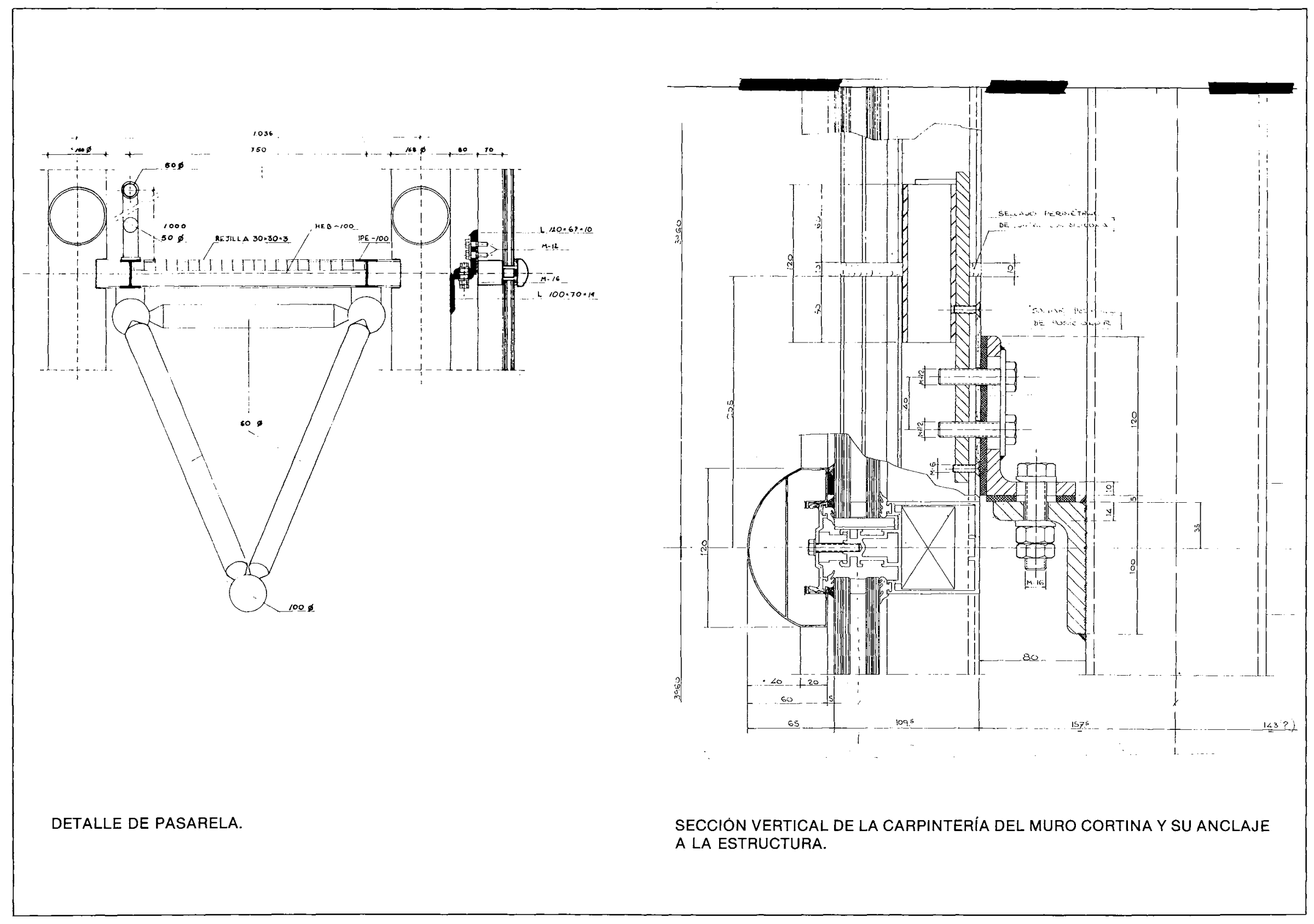




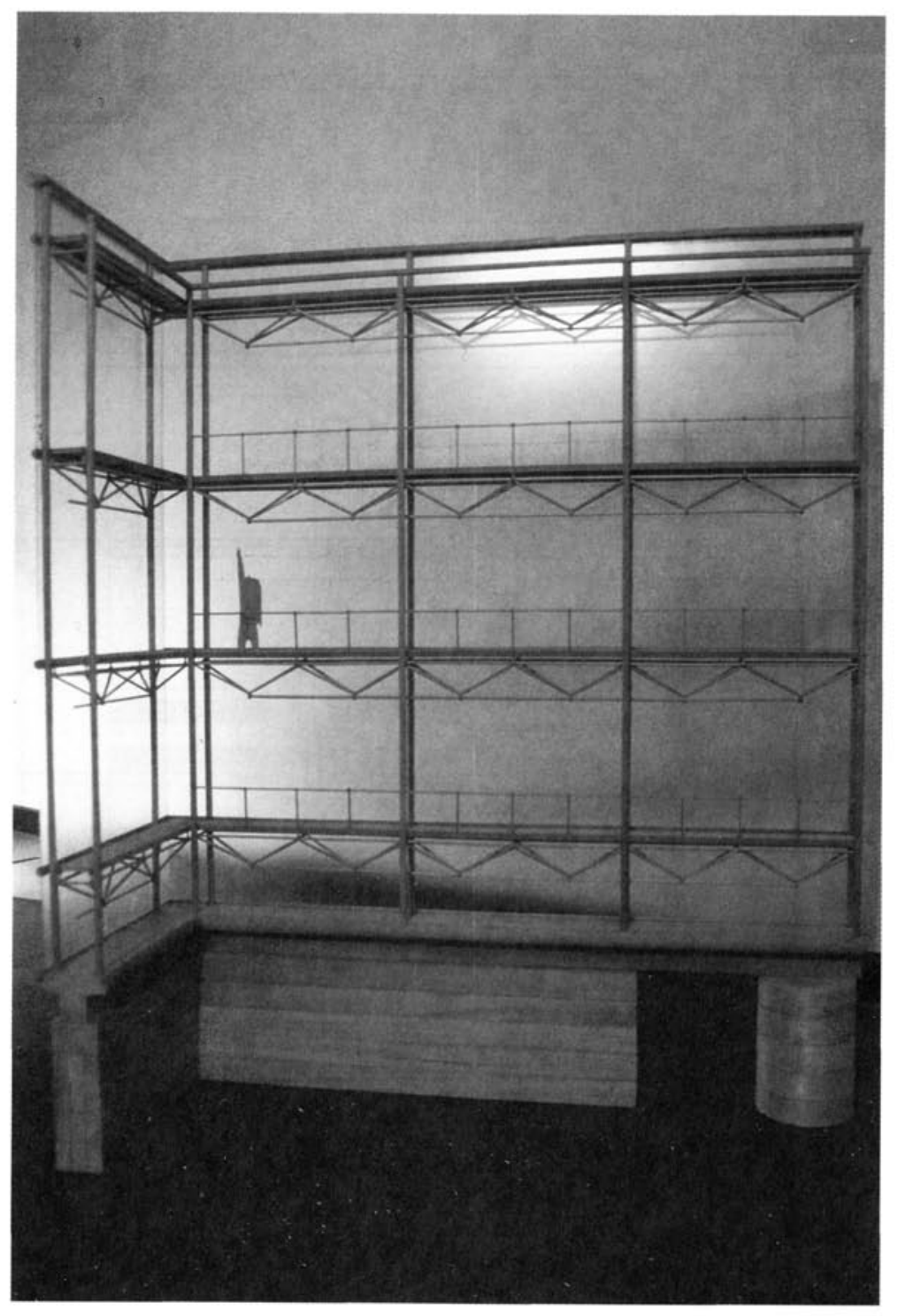

Ambos cerramientos, realizados a base de grandes lunas de vidrio, ofrecen soluciones constructivas distintas.

El cerramiento exterior se define a partir de una solución en muro cortina convencional, pero que en sus dimensiones y modulación enfatiza la horizontalidad de la composición deseada por los autores. Se utilizan lunas de 4,00 $\times 2,50 \mathrm{~m}$. La carpintería horizontal de "la rejilla" del muro ofrece al exterior la forma de una baqueta clásica, mientras la vertical (en su discrección) coincide con los pórticos de sustentación, que hacen de este cerramiento un "muro cortina exento" apoyado en su base.

El sistema de fijación de la rejilla a los pórticos de apoyo es el estandar: dos "L" metálicas con juego en las tres direcciones del espacio (Pág. 91). Las dilataciones del cerramiento son absorbidas por el juego de la carpintería y la independencia de la serie porticada, interrumpida en dos puntos a lo largo del alzado.
En cuanto a la limpieza del vidrio se ha tenido en cuenta: En su cara interior, un sistema de pasarelas fijas que permite su fácil acceso. En su cara exterior, al estar rodeado el edificio por una calle particular y ser éste de poca altura, permite su fácil limpieza a través de vehículos autónomos telescópicos sin necesidad de considerar la instalación de góndolas o similares.

Por otra parte, para la recogida del agua de cubierta se obvia la necesidad de canalones, y sencillamente se deja deslizar el agua sobre la fachada, hasta reco. gerla en un gran canalón situado en la parte superior del zócalo, que sirve de basamento a la fachada. Canalón que en el alzado aparece como un gran baquetón: junta entre piedra y vidrio.

Las características físicas del vidrio aislante compuesto por 2 lunas, cada una laminar, en vidrio doble: $(6+6)$ +(cámara)+Stadip $(5+5)$ en el color verde propio del vidrio. 

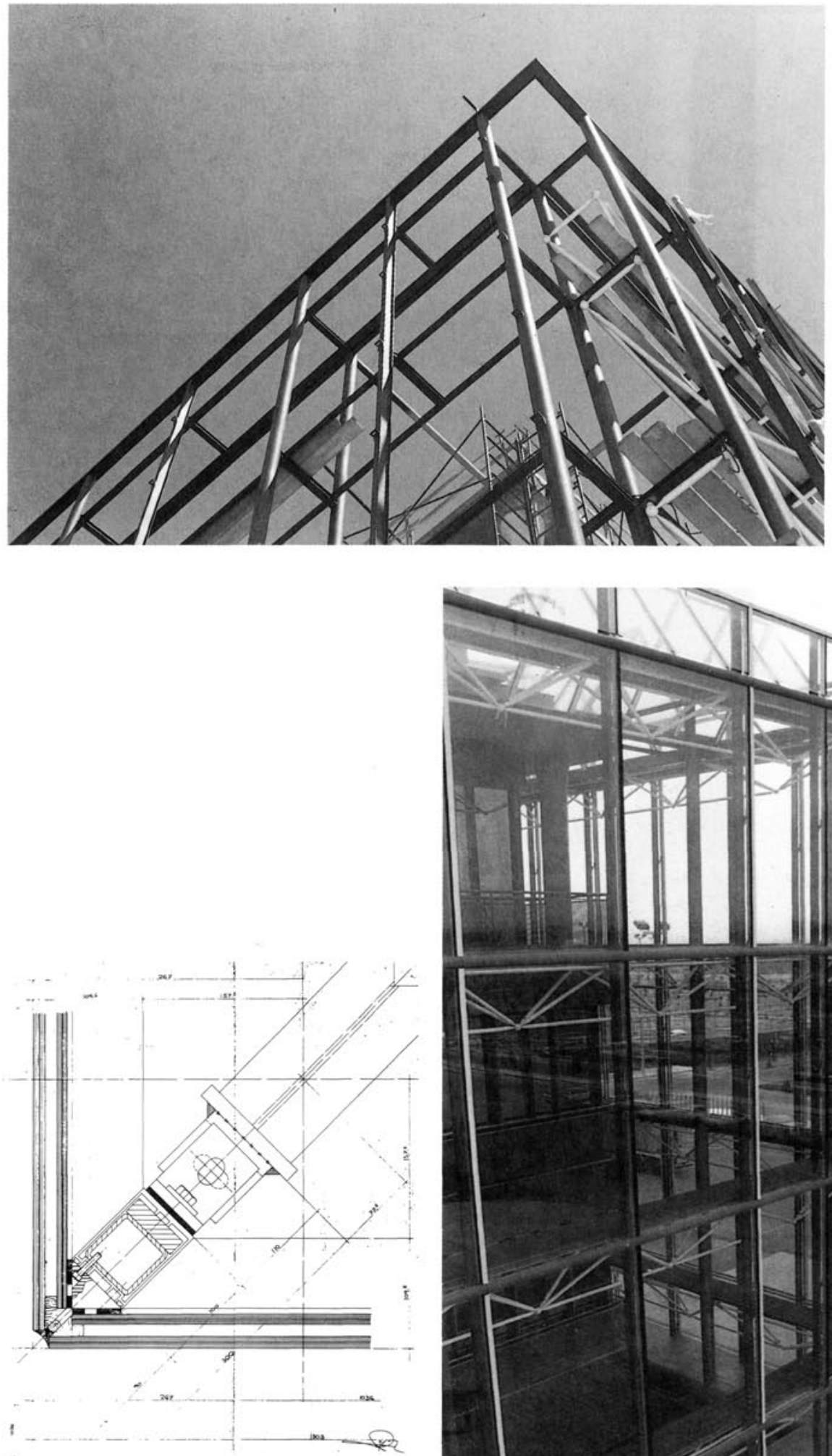

Detalle esquinero del muro cortina en cerramiento exterior.
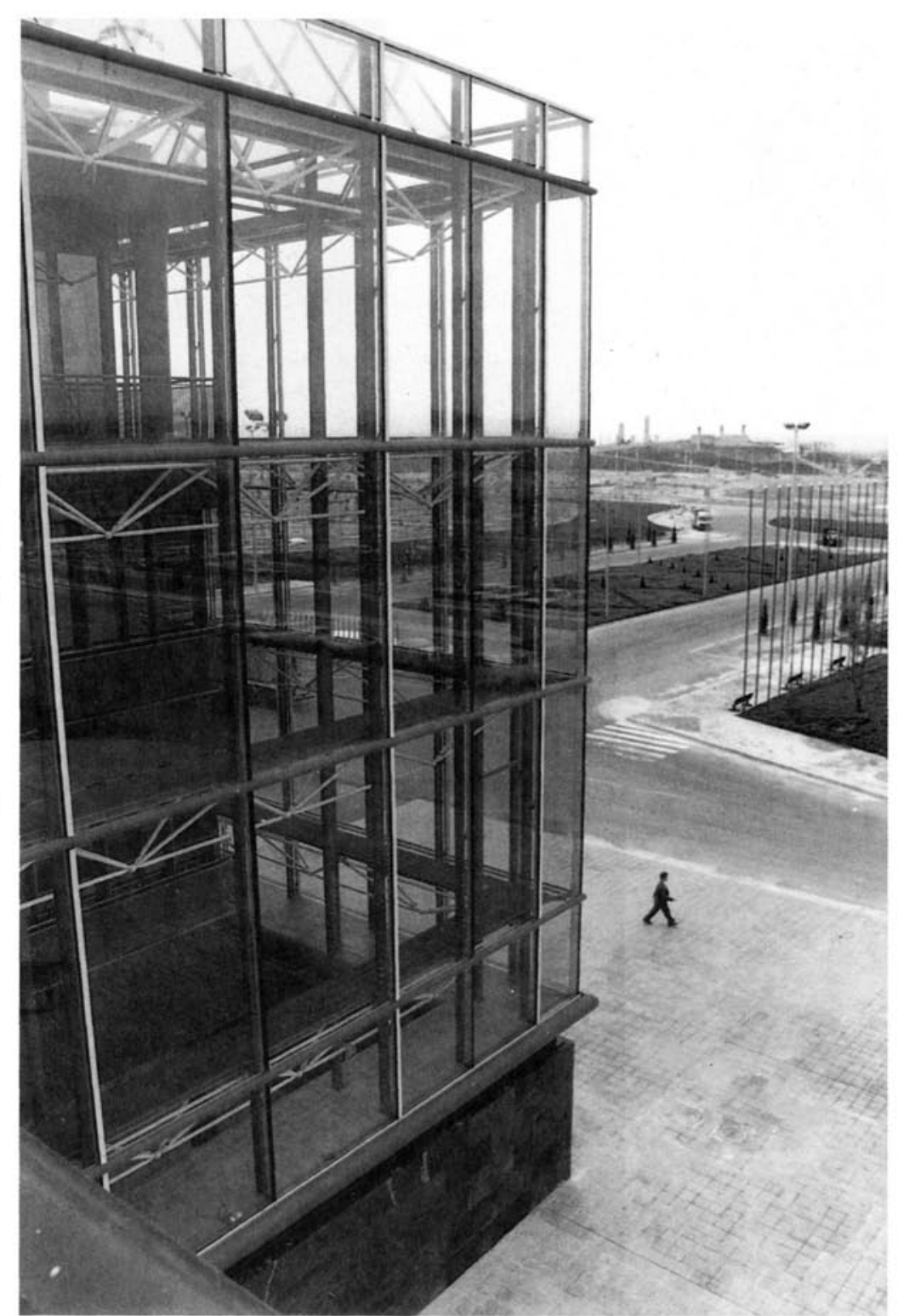


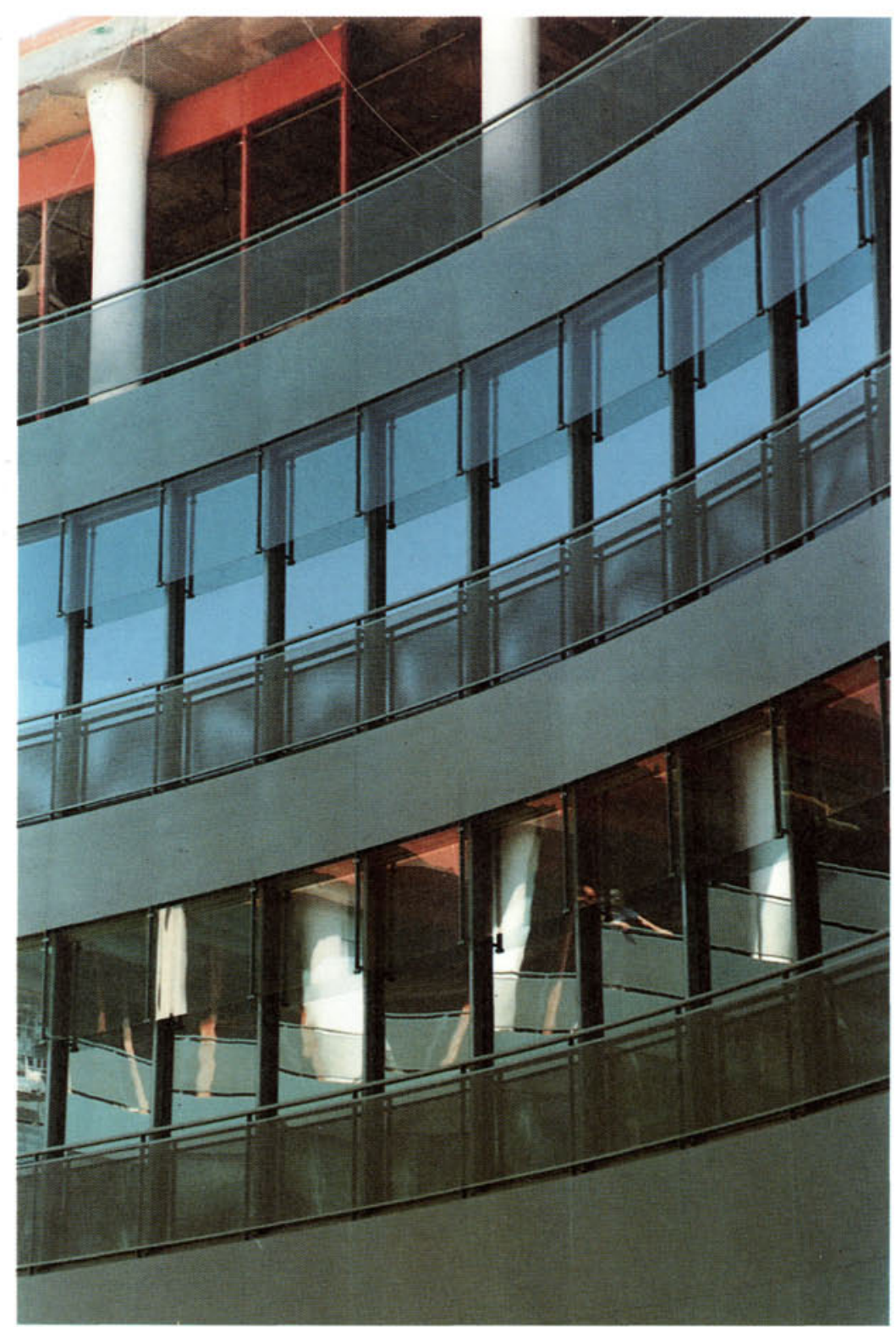




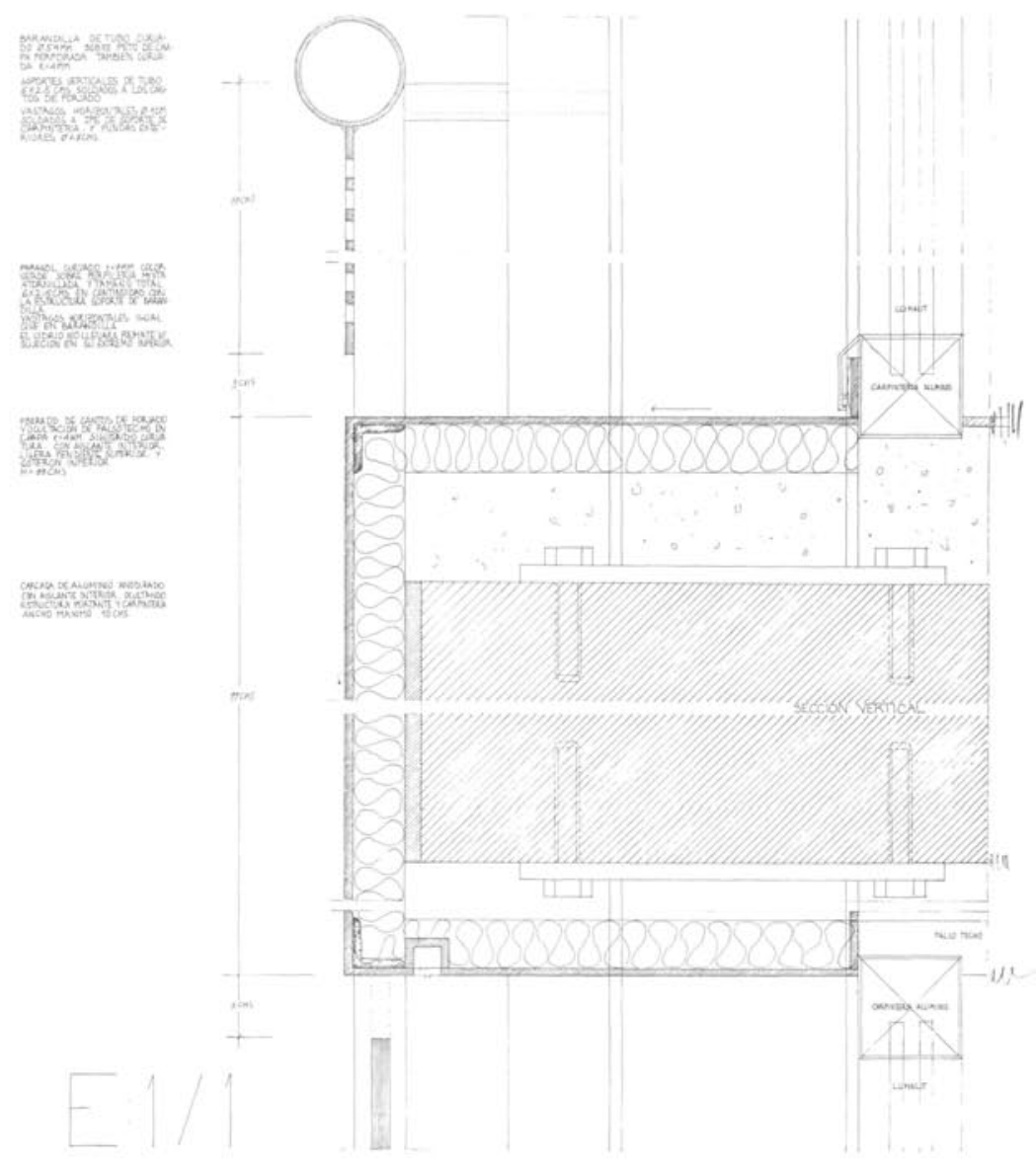

Plano de detalle en el borde de losas.

El gran tamaño de estos paneles aislantes $(4,00 \times 2,50)$ y su espesor hacen que, una vez colocados, el efecto planar de la fachada no sea el deseado: la presencia de "aguas" hace su aparición. Este defecto se corrige a base de inyectar aire en las cámaras de los paneles, a través de válvulas especiales incorporadas a la pieza de vidrio para este fin.

En el cerramiento interior se ha adoptado también por una solución modular, pero que, sin ser de muro cortina, permite el retranqueo del plano de fachada respec-

(c) Consejo Superior de Investigaciones Científicas Licencia Creative Commons 3.0 España (by-nc) to a los bordes de forjado. Así, se instalan antepechos y parasoles, a la vez que se permite la posibilidad de hacer practicable la fachada, para su limpieza, con una sencilla solución de carpintería. La dimensión de los vidrios es de $1,25 \times 3,00 \mathrm{~m}$, y también aislantes. Esta vez, a base de vidrio doble $(5+5)+($ cámara $)+(5+5)$, en un tono verde reflectante, que permite la transparencia de dentro hacia afuera y viceversa.

Superpuestos todos estos planos de materiales y calidades, sólo resta dejar que el edificio hable por sí mismo. 

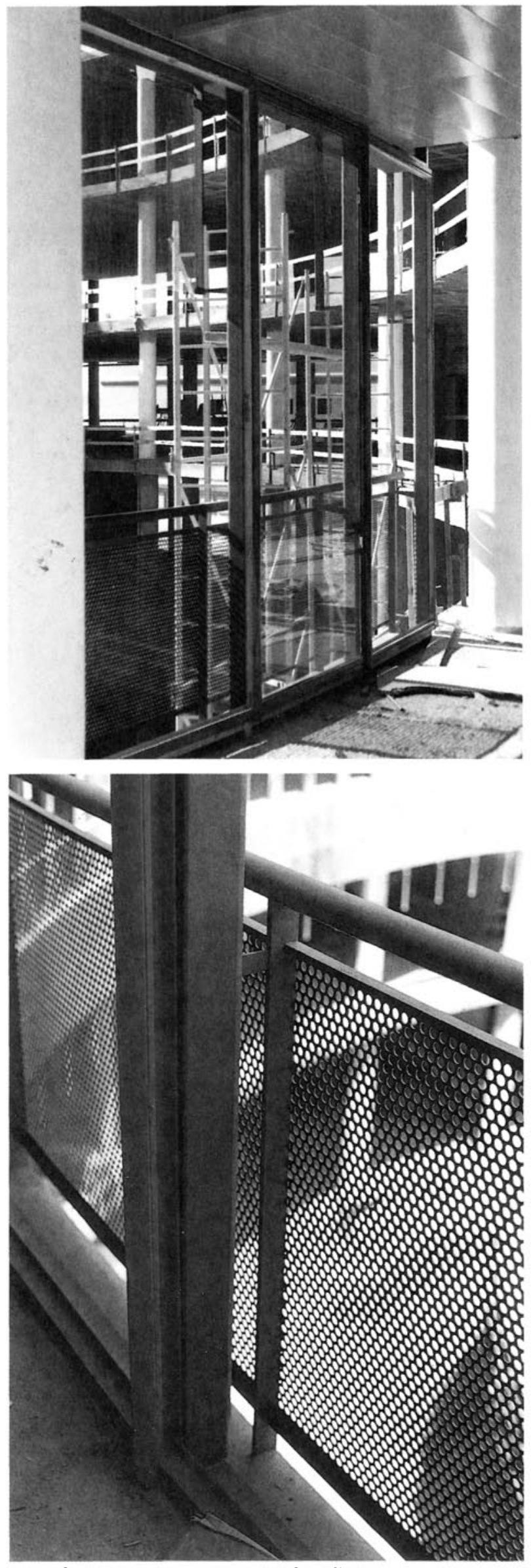

(c) Consejo Superior de Investigaciones Científicas Licencia Creative Commons 3.0 España (by-nc)

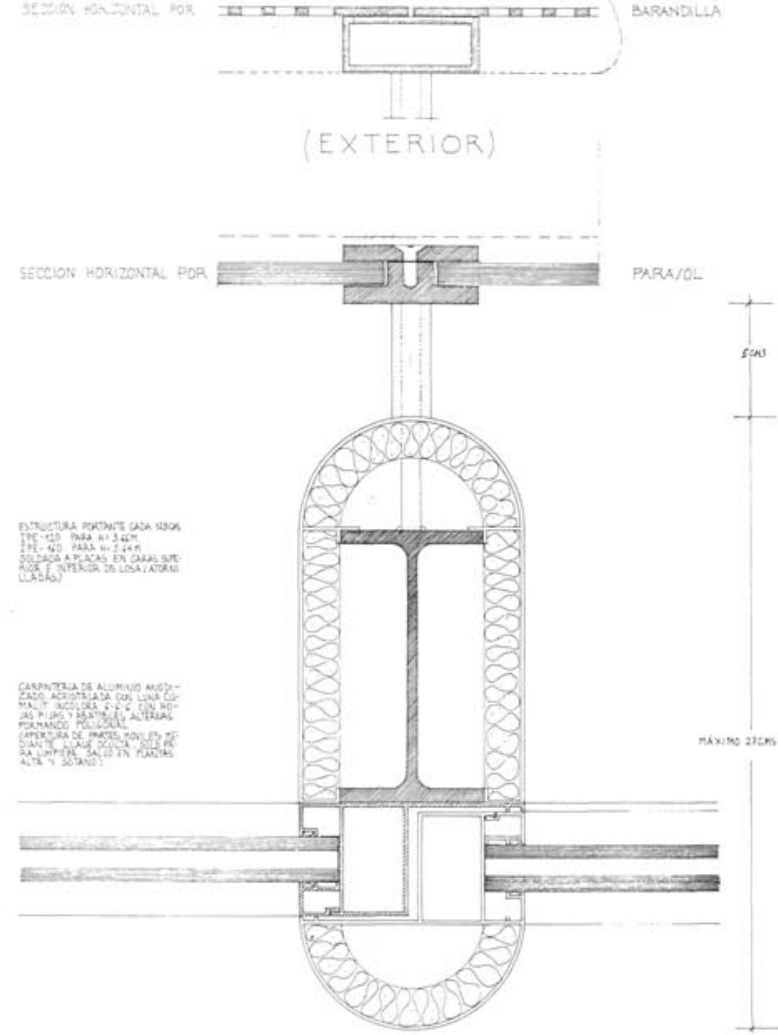

Plano de detalle inicial de carpintería en borde de losas. 


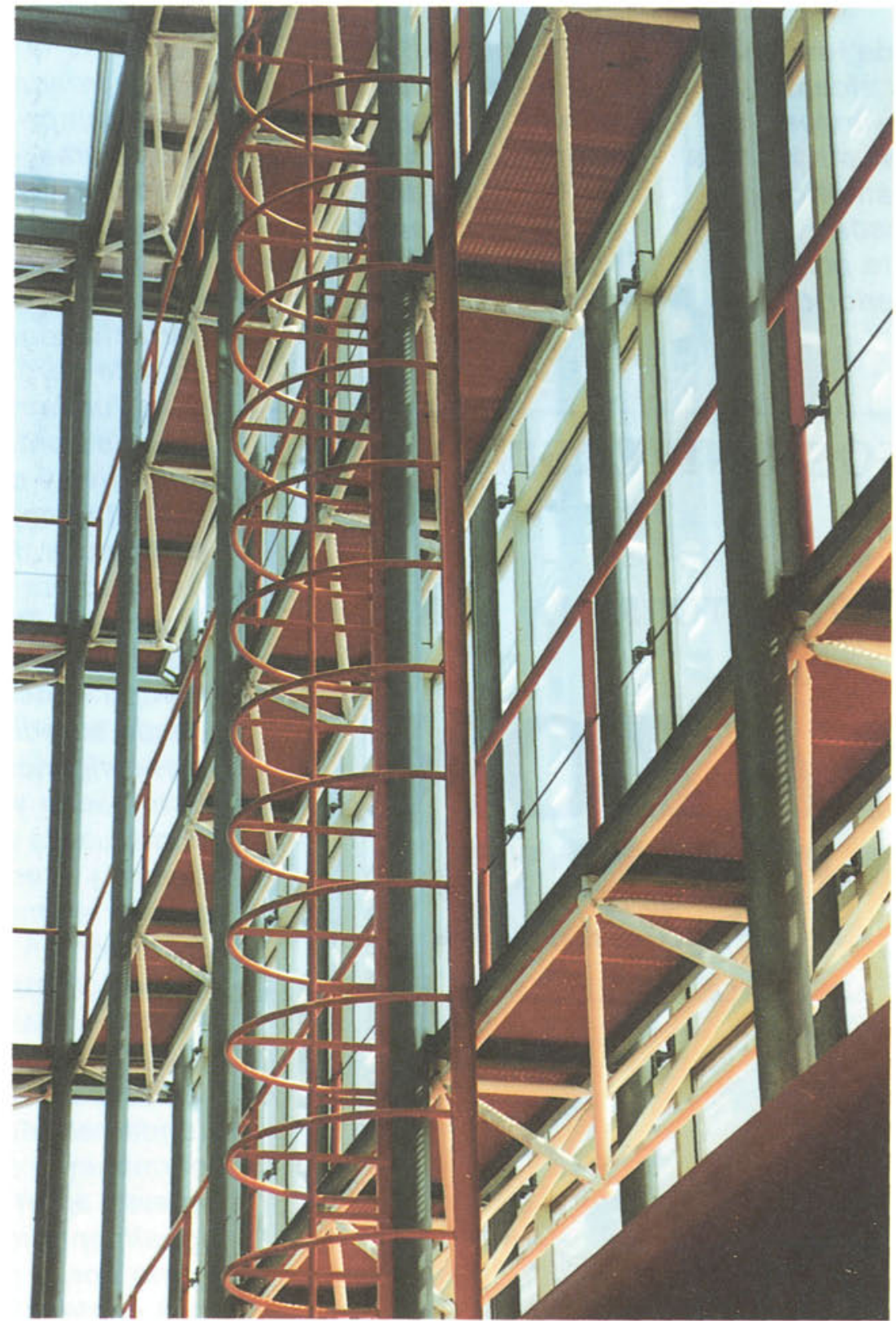

Equipo técnico

$\begin{array}{ll}\begin{array}{ll}\text { Arquitectos autores } \\ \text { del Proyecto: }\end{array} & \begin{array}{l}\text { Francisco Javier Sáenz Oiza } \\ \text { Francisco Oiza Cuadrado } \\ \text { Javier Sáenz Guerra }\end{array} \\ \text { Dirección de Obra: } & \begin{array}{l}\text { Los autores del Proyecto y } \\ \text { Luis García-Germán Polanco }\end{array} \\ \text { Empresa Constructora: } & \text { Cubiertas y MZV } \\ \text { Cerrajería: } & \text { Coloma } \\ \text { Propiedad: } & \text { IFEMA }\end{array}$

Fotografias: F. Oiza Cuadrado 